\title{
Empirical Research on Shanghai Residents' Financial Literacy
}

\author{
Hao Chen ${ }^{1}$, Yuxi Wang ${ }^{1}$, Shaohua Yang ${ }^{1} \&$ Haina Yuan ${ }^{1}$ \\ ${ }^{1}$ Management School, Shanghai University of Engineering Science, Shanghai, China \\ Correspondence: Hao Chen, Management School, Shanghai University of Engineering Science, Shanghai, China. \\ E-mail: chenhaoyidingxing@163.com
}

Received: November 10, 2013

Accepted: November 26, 2013

Online Published: January 10, 2014

doi:10.5430/ijfr.v5n1p101

URL: http://dx.doi.org/10.5430/ijfr.v5n1p101

This paper is supported by National Social Science Foundation of China (Project number 11CGL021) and Innovative Research Program for Postgraduates of Shanghai University of Engineering Science (Project number A-0903-13-01038).

\begin{abstract}
According to the research experiences of foreign financial literacy and China's actual needs, this paper divided Shanghai residents' financial literacy into three categories: financial knowledge level, behavior finance background and investment capabilitiy. Then set some related questions to investigate them successively, sorted out the basic data of shanghai residents' financial literacy and used average analysis and univariate analysis to process it. Firstly, this paper overviews the result of every question, then adds age, gender, degree and income as control variables to furtherly analyse the data of financial knowledge level, behavior finance background and investment capabilitiy, finally excavates potential value information, summarizes regular characteristics, and combines with the reform path of Chinese pension system and the trend of financial industry development to put forward specific recommendations and macro proposed measures to improve residents' financial literacy in Shanghai as well as the country.

Keywords: residents' financial literacy, financial knowledge level, behavior finance background, investment capability

\section{Introduction}

Financial literacy consists of knowledge, capability and mental cognition which help individuals effectively manage their financial assets and resources for their happy later life. Financial literacy can be expressed in three aspects which are right understanding of financial theory and products, assessment and tendency in financial environment and capability of using financial tools to complete capital planning.

Financial literacy has been popular in interactive research between finance and social security, many foreign scholars and governmental organizations find that as resident's life extends, problem of global ageing population will become more serious, countries' financial burdens will be bigger, so it is tendency that government will let residents take more responsibility for pension expenditure and have higher financial literacy to avoid appearing the big empty hole of national pension system. Foreign researches indicate that residents have low financial literacy in many countries now, which counts against their wealth accumulation and pension planning. There is no doubt that financial literacy is of great importance. PACFL said that American financial crisis in 2008 was emerged from many origins, but insufficient financial literacy was one of unfortunate origins. So it is urgent to conduct survey of residents' financial literacy in every country to make sense of the local residents' financial literacy and promote it.
\end{abstract}

\section{Literature Review}

In order to assess American residents' financial literacy, Lusardi and Mitchell (2007, 2008, and 2011) followed four core principles which include simplicity, relationship, succinct and distinction. Bucher-Koenen and Lusardi (2011) got conclusions through SAVE survey (One survey aimed at German household) that financial literacy have positive influence on retirement planning; female, low education degree and lived in eastern Germany lack of basic financial literacy. Fornero and Monticone (2011) used new questions to measure financial literacy and explored the impacts on population distribution and retirement planning in Italy. Empirical results show that the majority of the Italian people lack basic financial concepts, they know more about the stock market and inflation than the interest rates. Klapper and Panos (2011) used the data information obtained by interviewing 1400 respondents in 2009 to analyse financial literacy, research of financial literacy in Russia and retirement planning found that only $36 \%$ of the espondents understood the 
compound interest; only half can answer simple questions about inflation. In addition, Arrondel (2012) in France, Cole (2011) and Atkinson (2011) in Mexico, Chile, India and Indonesia and other countries expanded financial literacy survey. These countries vary in location and stage of development, but the survey results reflect the consistency and high credibility in these countries.

Chinese residents' disposable income and risk-resisting ability are all inadequate, the rising future price and coming aging society will increase pension pressure of different age groups, it also will bring a huge financial pressure to the government and cause social crisis. So we should accelerate financial literacy survey of residents in China. In this paper, Shanghai residents were chosen as survey sample, summerized financial literacy of Shanghai residents through the investigation and analysis, and found approaches to improve the financial literacy.

\section{Survey Content and Sample Description}

\subsection{Survey Content}

In order to objectively measure the accurate financial literacy of Shanghai residents, we refer to the definition of financial literacy and experience from the foreign scholars and institutions, divided financial literacy survey investigation into three categorie: financial knowledge level, behavior finance background and investment capability. Take examples from financial literacy survey of U.S. residents designed by Annamaria we designed eight questions to assess financial literacy level, which contained relation between security and interest, inflation, compound interest, risk diversification, time value, relation between security and bonds, stock definition and bonds definition. These questions are simple and about the basic financial knowledge. Behavior finance background is mainly assessed from income assessment, risk preference, pension pressure. Investment capability is mainly assessed from investment approaches of residents, investment reference information and insurance purchase.

\subsection{Sample Description}

This survey was targeted at the general people of Shanghai, took random survey method to issure 500 questionnaires, excluding invalid answer questionnaires, and finally got 358 valid questionnaires, sample pass rate was $71.6 \%$.

\section{Summary of Statistical Results}

\subsection{Financial Knowledge Level}

The financial knowledge level is determined by the correct rate of answering the eight questions. Through this survey calculating the average score of Shanghai residents was 53.63 points, yet less than 60 points, the traditional sense of passing level. It reflects their financial knowledge level is not high. The sample standard deviation is 27.69 points, scores fluctuate strongly among individuals, and the scores of residents in financial knowledge are uneven. Skewness is -0.10 , close to 0 , indicates that the scores almost symmetrically distribute two sides of the average score. These eight questions are closely related to the daily lives of residents, residents should have known, but the findings are worrisome. The question of inflation had the highest correct rate of $73 \%$, Chinese continued inflation had made residents familiar with it. The relationship between interest rates and stock and bonds definition have the lowest correct rate of $41 \%$. Question of compound interest answered correctly with $45 \%$, question of risk diversification was $59 \%$, question of time value was $57 \%$, stock definition was $49 \%$, and the relationship between stocks and bonds was $62 \%$. This situation reflects that financial knowledge of residents needs to be improved.

Table 1. Assessment results of the financial knowledge level

\begin{tabular}{ccccc}
\hline Statistics & Mean & Std & Skewness & Kurtosis \\
\hline Average score & 53.63 & 27.69 & -0.10 & -0.9 \\
Relation between Security and interest & 0.41 & 0.49 & 0.35 & -1.89 \\
Inflation & 0.73 & 0.45 & -1.04 & -0.93 \\
Compound interest & 0.45 & 0.50 & 0.19 & -1.97 \\
Risk diversification & 0.59 & 0.49 & -0.38 & -1.8 \\
Time value & 0.57 & 0.50 & -0.30 & -1.9 \\
Relation between security and bonds & 0.62 & 0.49 & -0.50 & -1.76 \\
Stock definition & 0.50 & 0.50 & 0.01 & -2.01 \\
Bonds definition & 0.41 & 0.49 & 0.35 & -1.89 \\
\hline
\end{tabular}

\subsection{Behavior Finance Background}

The diversity of financial products inevitably suffers psychological and behavioral statuss, results in different financial decision of individuals (Xindan L et al, 2011). Therefore, investigation of financial literacy can not lack of investigation of behavior finance background. The following will introduce behavior finance background from income 
assessment, risk preference and pension pressure of Shanghai residents.

Table 2. Stastics results of behavior finance background

\begin{tabular}{cccc}
\hline Statistics & Options & Number of people & Percentage \\
\hline \multirow{2}{*}{ Income assessment } & Very satisfied & 13 & $3.63 \%$ \\
& Satisfied & 44 & $12.29 \%$ \\
& A little satisfied & 69 & $19.27 \%$ \\
& Dissatisfied & 175 & $48.88 \%$ \\
risk preference & Very dissatisfied & 57 & $15.92 \%$ \\
& High risk and high return & 57 & $15.92 \%$ \\
& Medium risk and medium return & 198 & $55.31 \%$ \\
& Low risk and low return & 116 & $32.40 \%$ \\
\hline Pension pressure & Tremendous & 31 & $8.66 \%$ \\
& Large & 107 & $29.89 \%$ \\
& General & 178 & $49.72 \%$ \\
& Small & 24 & $6.70 \%$
\end{tabular}

\subsubsection{Income Assessment}

Income assessment reflects income satisfaction of residents. Table 2 reveals there were $15.92 \%$ of the people in this suvery feeling very dissatisfied and $48.88 \%$ feeing dissatisfied with there income level. In addition, there were $19.27 \%$ of people feeling a little satisfied, $12.29 \%$ feeling satisfied and only $3.63 \%$ feeling very satisfied with their income level. This shows that dissatisfied income ratio are far more than satisfied income ratio. China's current income level is not high, most of the residents are not satisfied with their income status, and the income assessment suggests the balance of payments to a certain extent, which would affect the residents' investment behavior.

\subsubsection{Risk Preference}

As table 2 describes, there were $55.31 \%$ of the sample choosing medium risk and medium return in risk preference, $32.40 \%$ choosing low risk and low return, less than $16 \%$ choosing high risk and high return. We can see that Shanghai residents prefer low risk investment, can't withstand investment fails, and unwill to participate in high risk and high return investments. But residents in our country are unable to get higher returns through the low risk, the earning part is fewer than the increasing cost from rising prices, it is actually carrying on a negative rate investment.

\subsubsection{Pension Pressure}

According to the survey on pension pressure, there were $8.66 \%$ of the sample feeing tremendous pension pressure and $29.89 \%$ feeling large pension pressure. The number of people chosen very small pension pressure was $6.7 \%$, small pension pressure was $5.03 \%$, and medium pension pressure was $49.72 \%$. It can be seen that Shanghai residents are more inclined to worry their futurous pension pressure.

\subsection{Capability of Investment}

Table 3. Statistics result of investment capability (Multiple choices)

\begin{tabular}{|c|c|c|c|}
\hline Statistics & Option & Number of people & Percentage \\
\hline \multirow{7}{*}{ Investment approaches } & Stocks & 68 & $18.99 \%$ \\
\hline & Funds & 53 & $14.80 \%$ \\
\hline & Deposit & 280 & $78.21 \%$ \\
\hline & Bonds & 21 & $5.87 \%$ \\
\hline & Bank financial products & 57 & $15.92 \%$ \\
\hline & Real estate & 60 & $16.76 \%$ \\
\hline & Other & 74 & $20.67 \%$ \\
\hline \multirow{3}{*}{$\begin{array}{l}\text { Investment Reference } \\
\text { Information }\end{array}$} & Parents, friends or relatives & 199 & $55.59 \%$ \\
\hline & TV or newspapers & 141 & $39.39 \%$ \\
\hline & Financial magazines or books & 65 & $18.16 \%$ \\
\hline
\end{tabular}




\begin{tabular}{cccc} 
& Bank or mortgage adviser & 36 & $10.06 \%$ \\
& Financial consulting firm & 58 & $16.20 \%$ \\
& Financial software & 9 & $2.51 \%$ \\
& Network & 114 & $31.84 \%$ \\
Insurance Purchase & Other & 48 & $13.41 \%$ \\
& Commercial pension insurance & 94 & $26.26 \%$ \\
& Accidental injury insurance & 159 & $44.41 \%$ \\
& Critical illness insurance & 87 & $24.30 \%$ \\
& Property insurance & 40 & $11.17 \%$ \\
& Other insurance & 101 & $28.21 \%$ \\
\hline & Uninsured & 76 & $21.23 \%$ \\
\hline
\end{tabular}

\subsubsection{Investment Approaches}

As table 3 shows on the approaches of daily residents' investment, there were $78.21 \%$ of the sample choosing deposits, far more than other options. It means residents regard deposits as the most important investment way and unwill to opt for a relatively large risk investment. Stocks, funds and bank financial products were all only about $15 \%$ of the sample selection. Real estate investment in China is more popular to residents, $16.76 \%$ of the sample selection was real estate. Thus, China's high savings rate, few investment products for residents and inefficient in investment are not surprising.

\subsubsection{Investment Reference Information}

When making important investment decisions, more than half of respondents got the reference information from parents, friends or relatives reached $55.59 \%$. We can see residents prefer the reference investment information from the people around them. Traditional television, newspapers and network were $33.39 \%$ and $31.84 \%$ of sample choosing. Financial magazine and book was only $18.16 \%$ of sample choosing. Bank or mortgage advisers, financial consulting companies, financial software choices were lesser. The advice from family, friend, traditional mass media and network are playing important role on residents' financial decisions.

\subsubsection{Insurance Purchase}

The vast majority of residents have purchased the insurance, while uninsured people were only $21.23 \%$. In the insurance categories of purchase, accidental injury insurance had the highest rate buyers of $44.41 \%$, critical illness insurance had $24.3 \%$ rate. It indicates that residents are most concerned about security and health. the rate of purchasing commercial pension insurance reached $26.26 \%$, which means these residents are starting to focus on the pension issue, but compared with the national pension plan, this data is not very satisfactory. In addition, the property insurance buyers reached $11.17 \%$.

\section{Statistics Summary Contained Three Types of Control Variables}

We set the following quantitative criteria to quantify the question choice situations of behavior financial background and investment capability. The quantitative score of 1,2,3,4 and 5 are corresponding to five options of income assessment very dissatisfied, dissatisfied, a little satisfied, satisfied, very satisfied. The big number is the more satisfied is. The quantization of pension pressure option is similar to income assessment, the bigger number the more pressure. Three options of risk preference the low risk and low return, medium risk and medium return, high risk and high return are corresponding to the quantitative score of 1,3 and 5. Because investment approaches, investment reference information and insurance purchase are multiple choices questions, so used 5 cuouterpoint to quantify their options status. The quantitative score is equal to the number of choices respondent chose unless beyond 5 , when beyond 5 the quantitative score is also 5.

\subsection{The Classification Summary of Financial Knowledge Level}

\subsubsection{Youth Is Significantly Higher than Olders}

Table 4 shows young people of 18-25 years old had the highest financial knowledge score, while people of 36-55 years old had the lowest financial knowledge score, financial knowledge score of 55 and above years old people are also very low, less than 40 points. People younger than 36 years old had higher level of financial konwledge than people older than 36 years old, which is the same with the foreign findings. Investment decisions require higher level of financial knowledge, this score is significantly low.

\subsubsection{Male Are Higher than Female}

The average score of financial knowledge for male was 58.15 points while for female was just 49.17 points. Reflecting the financial knowledge level for male is better than for female, which is also the same with foreign research conclusions. 


\subsubsection{Degree Has a Positive Impact}

Financial knowledge score of primary education was 34.59 points, high school or college degree had the score of 42.68 points, undergraduate degree was 63.43 points, master's degree was 80.39 points, and doctor degree was 81.25 points. The survey finds that the higher the degree is the higher financial knowledge level is. Finding is also the same with foreign conclusion. Financial knowledge scores are increasing with degree, and the score of master degree is close to doctor degree, shows people can't correctly answer the eight simple questions even if they have high education background.

\subsubsection{Income Level Does Not Determine the Level of Financial Knowledge}

In table 4, the residents whose annual income below 30,000 yuan had financial knowledge score of 57.38 points, $30,000-50,000$ yuan residents had the score of 47.61 points, 50,000-100,000 yuan residents had the score of 48.75 points, 100,000-200,000 yuan residents had the score of 62.50 points, 200,000 and above residents had the score of 43.75 points, the highest score belonged to $100,000-200,000$ yuan residents. 30,000 yuan was also high because it contained students in the school, so the score reached 57.38. The above analysis shows income levels and financial knowledge levels are not perfectly correlated.

\subsection{Classification Summary of Behavior Finance Background}

Table 4. Three aspects of financial literacy statistics under different conditions

\begin{tabular}{ccrrrrrrr}
\hline Category & Subcategory & $\begin{array}{c}\text { Fiancial } \\
\text { knowledge }\end{array}$ & $\begin{array}{c}\text { Income } \\
\text { level }\end{array}$ & $\begin{array}{c}\text { Risk } \\
\text { preference }\end{array}$ & $\begin{array}{c}\text { Pension } \\
\text { pressure }\end{array}$ & Investment & $\begin{array}{c}\text { Investment } \\
\text { reference }\end{array}$ & $\begin{array}{c}\text { Insurance } \\
\text { purchase }\end{array}$ \\
\hline \multirow{5}{*}{ Ages } & $18-25$ & 62.43 & 2.20 & 2.80 & 3.26 & 1.80 & 2.14 & 1.43 \\
& $26-35$ & 52.74 & 2.52 & 2.57 & 3.43 & 1.71 & 1.87 & 1.49 \\
& $36-55$ & 33.33 & 2.62 & 2.29 & 3.29 & 1.40 & 1.33 & 1.20 \\
\multirow{3}{*}{ Gender } & 55 and above & 38.64 & 2.71 & 2.26 & 3.30 & 1.61 & 1.18 & 0.93 \\
& Male & 58.15 & 2.45 & 2.77 & 3.29 & 1.78 & 1.92 & 1.39 \\
& Female & 49.17 & 2.33 & 2.47 & 3.32 & 1.80 & 2.14 & 1.43 \\
\hline \multirow{6}{*}{ Degree } & Secondary and below & 34.59 & 2.67 & 2.08 & 3.33 & 1.27 & 1.26 & 0.92 \\
& High school or college & 42.68 & 2.33 & 2.48 & 3.32 & 1.59 & 1.54 & 1.26 \\
& Undergraduate & 63.43 & 2.47 & 2.85 & 3.26 & 2.00 & 2.25 & 1.63 \\
& Master & 80.39 & 1.94 & 3.08 & 3.41 & 1.84 & 2.45 & 1.49 \\
& Doctor & 81.25 & 1.50 & 4.00 & 1.50 & 2.00 & 2.50 & 2.00 \\
Income & Below 30,000 & 57.38 & 2.17 & 2.57 & 3.32 & 1.63 & 1.96 & 1.20 \\
level & 30,000-50,000 & 47.61 & 2.43 & 2.43 & 3.54 & 1.51 & 1.70 & 1.29 \\
& 50,000-100,000 & 48.75 & 2.80 & 2.68 & 3.20 & 1.92 & 1.74 & 1.92 \\
& $100,000-200,000$ & 62.50 & 2.79 & 3.17 & 3.00 & 2.42 & 1.92 & 1.83 \\
& 200,000 and above & 43.75 & 2.83 & 3.50 & 2.42 & 2.00 & 1.83 & 1.75 \\
\hline
\end{tabular}

5.2.1 Age Is Positive to Income Assessment

In income assessment, residents of 18-25 years old had the lowest satisfaction rate of four age ranges because they had the lowest average score. Young people had a little income or no income, so they had the lowest satisfaction. The residents above 55 years old had the highest income satisfaction rate, indicating that they easily meet their income expectation compared with other three age ranges. The average score of income assessment from young to middle-aged and elderly gradually increased, so age has a positive effect on income assessment.

\subsubsection{Age Has a Direct Relationship with Risk Preference}

In risk preference, residents of 18-25 and 26-35 years old had higher risk preference score, but residents of 36-55 and above years old had lower risk preference score. Younger residents prefer to accept high-risk investments compared with old residents. The young can appropriately select high-risk investment with high-income, the elderly should be cautious on investment. Their risk preferences are consistent with common sense.

\subsubsection{Income Assessments and Risk Preferences Are Different in Terms of Gender}

Income assessments and risk preferences greatly vary in gender compared with pension pressures. Especially in risk preference, the average score of male was a little bigger than the average score of female.

5.2.4 Degree Directly Affects the Income Assessment and Risk Preference

Income assessment is almost the higher degree with the lower score, indicates higher degree residents are more 
dissatisfied with their income level. This is a profound social problem. High degree does not bring high income and high income satisfaction, which goes against the proverb "A book holds a house of gold".

\subsection{Classification Summary of Investment Capability}

\subsubsection{The Young Are Stronger than the Elderly}

Table 4 shows that the score level of the young (18-35 years old) in investment approaches, investment reference information, insurance purchase are significantly higher than the scores level of the elderly (above 35 years old), showing their ability in finance and investment are stronger than the elderly, have a variety of investment approaches and reference informations, stronger capability and willingness.

\subsubsection{Higher Degree High Investment Capability}

Undergraduate, master and doctor degree residents on investment approaches, investment reference information and insurance purchase are significantly higher than high school or college, secondary and below education residents in scores. Better educational environment, broader range of knowledge and broader perspective make higher degree residents have better investment capability.

\section{Conclusion}

(1) The result of financial knowledge shows that Shanghai residents lack calculations ability of finance and demand of the interest rate. So we should strengthen financial education for residents and enhance their capability on finance and investment.

(2) Chinese residents are keen on savings, while other investment opporaches are low participation. High savings is not conducive to the consumer of residents, and they can not increase their value under inflation. It is time to create more new investment patterns not only promote economic development and aslo help icrease household wealth.

(3) Dissatisfied income assessment accounted for more than $60 \%$ of all income assessment, indicating the dissatisfaction of residents on income distribution. Government should accelerate the advance of income level for low income residents and the implementation of national wealth distribution plan as soon as possible. Then residents would have the ability to participate in finance and investment, improve financial literacy.

(4) Financial literacy of residents above 35 years old, female, high school or less degree is lower; the levels of financial knowledge and investment capabilities are lower than the average level of society. If conditions are all met the financial literacy would be serious shortage. So we must speed up financial education for these vulnerable residents, establish the right cognitive of behavior finance and foster financial investment capability, focus on improving their financial literacy.

\section{References}

Arrondel, L., Debbich, M., \& Savignac, F. (2012). Stockholding and Financial Literacy in the French Population. International Journal of Social Sciences and Humanity Studies, 4(2), 1309-8063.

Atkinson A., \& Messy, F. A. (2011). Assessing Financial Literacy in 12 Countries: An OECD Pilot Exercise. Journal of Pension Economics and Finance, 10(4), 657-665. http://dx.doi.org/10.1017/S1474747211000539

Bucher-Koenen, T., \& Lusardi, A. (2011). Financial literacy and retirement planning in Germany. Journal of Pension Economics and Finance, 10(4). 565-584. http://dx.doi.org/10.1017/S1474747211000485

Cole, S., Sampson, T., \& Zia, B. (2011). Prices or Knowledge? What Drives Demand for Financial Services in Emerging Markets. Journal of Finance, 66(6), 1933-1967. http://dx.doi.org/10.1111/j.1540-6261.2011.01696.x

Fornero, E., \& Monticone, C. (2011). Financial literacy and pension plan participation in Italy. Journal of Pension Economics and Finance, 10(4), 547-564. http://dx.doi.org/10.1017/S1474747211000473

Klapper, L., \& Panos, G. A. (2011). Financial literacy and retirement planning: the Russian Case. Journal of Pension Economics and Finance, 10(4). 599-618. http://dx.doi.org/10.1017/S1474747211000503

Lusardi, A., \& Mitchell, O. S. (2007). Baby Boomer Retirement Security: The Roles of Planning, Financial Literacy, and Housing Wealth. Journal of Monetary Economics, 54, 205-224. http://dx.doi.org/10.1016/j.jmoneco.2006.12.001

Lusardi, A., \& Mitchell, O. S. (2008). Planning and Financial Literacy: How Do Women Fare. American Economic Review, 98(2), 413-417. http://dx.doi.org/10.1257/aer.98.2.413

Lusardi, A., \& Mitchell, O. S. (2011). Financial Literacy and Retirement Planning in the United States. Journal of Pension Economics and Finance, 10(4), 509-525.

Xindan, L., Binqing, X., Honghai, Y., \& Jianhua, S. (2011). Survey of household finance. Journal of Management Science in China, 14(4), 74-78. http://dx.doi.org/10.1017/S147474721100045X 